\title{
The importance of overcoming MOVPE surface
}

\section{evolution instabilities for $>1.3 \mu \mathrm{m}$ metamorphic}

\section{lasers on GaAs}

Enrica E. Mura, ${ }^{* \dagger}$ Agnieszka M. Gocalinska, ${ }^{\dagger}$ Megan O’Brien, ${ }^{\dagger}$ Ruggero Loi,,${ }^{\dagger} \S$ Gediminas Juska, ${ }^{\dagger}$ Stefano T. Moroni, ${ }^{\dagger}$ James $O{ }^{\prime}$ Callaghan, ${ }^{\dagger}$ Miryam Arredondo, ${ }^{¥}$ Brian Corbett, ${ }^{\dagger}$ and Emanuele Pelucchi†

† Tyndall National Institute, “Lee Maltings”, University College Cork, Cork, Ireland $\S$ X-Celeprint Limited, Lee Maltings, Dyke Parade, Cork, Ireland

${ }^{¥}$ School of Mathematics and Physics, Queen’s University Belfast, Belfast, BT7 1NN, United Kingdom 

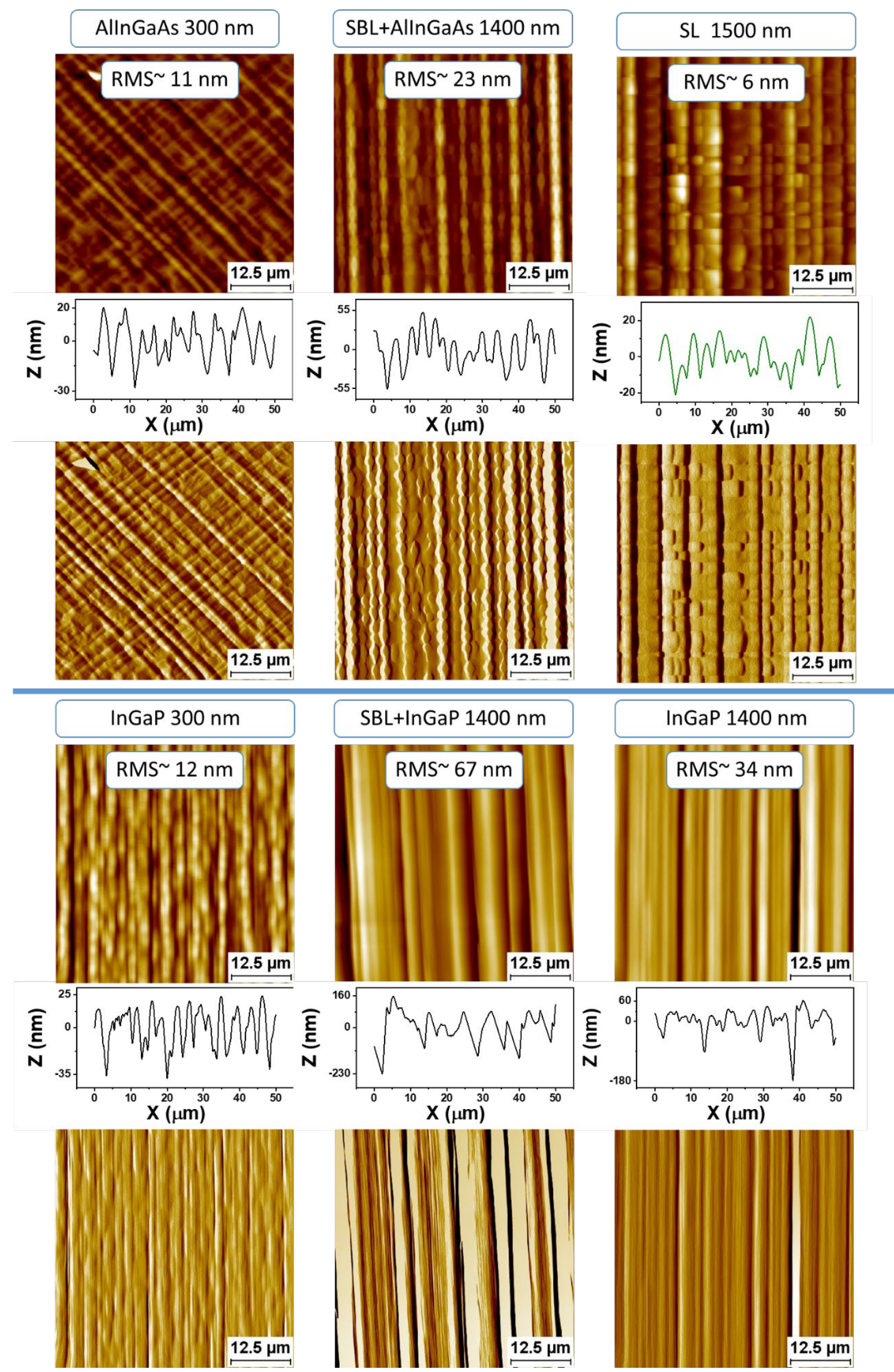
Figure S1. Surface morphologies (AFM signal amplitudes and height, Z in $\mathrm{nm}$ ) of samples with various cladding designs. Comparison between different cladding and the combined superlattice SL structures in terms of AFM height and amplitude signal, cross-sectional profiles, thickness and RMS value. All samples presented here were grown on perfectly oriented GaAs substrates or misoriented of $0.2^{\circ}$ towards [111]A. SBL indicates a strain balancing layer.
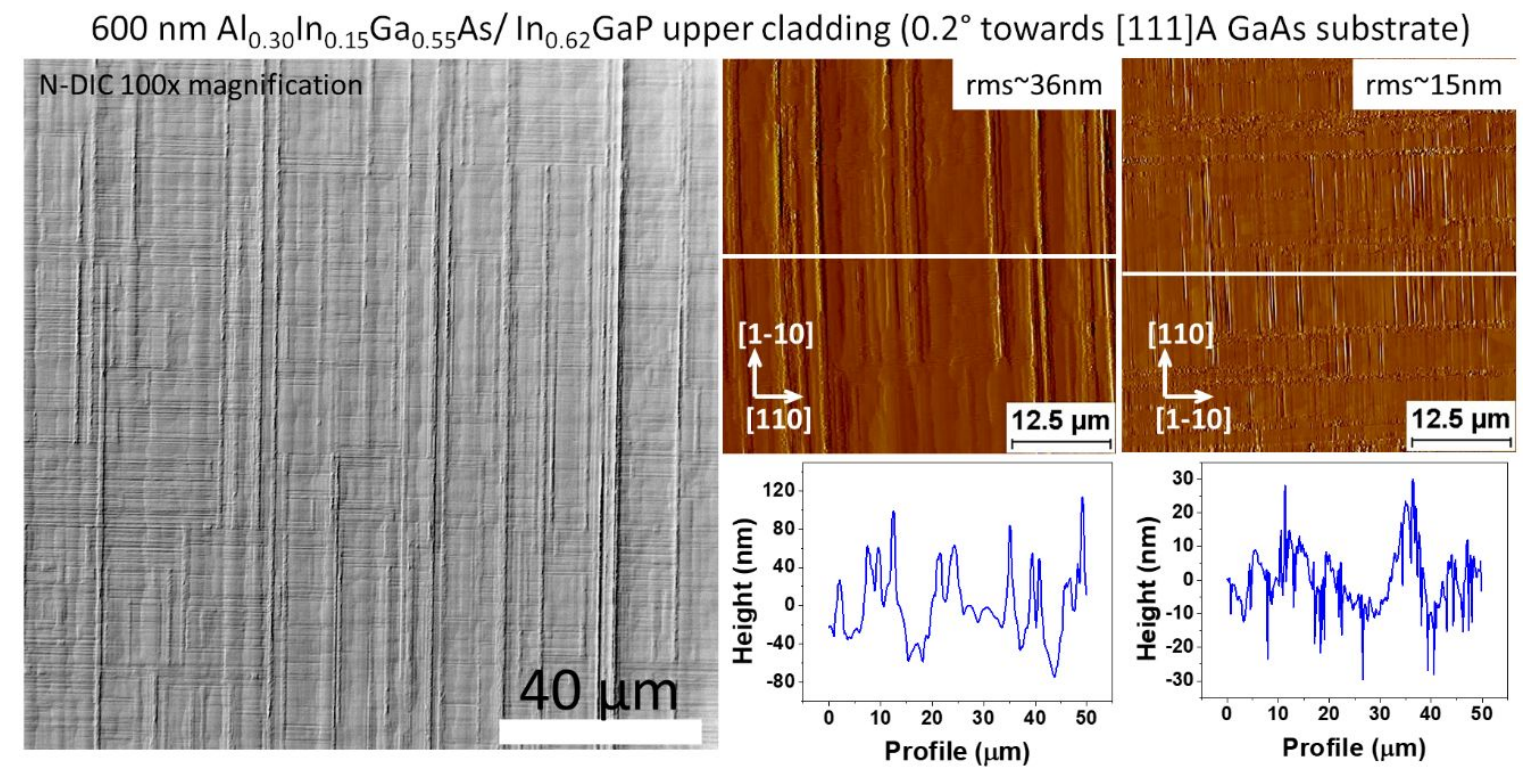

Figure S2. (Nomarski) Differential Interference Contrast and AFM (signal amplitude and cross-sectional profile) images of SL upper cladding grown at the end of active part, with following layer sequence: $250 \mathrm{~nm}$ of $\mathrm{Al}_{0.31} \mathrm{In}_{0.15} \mathrm{Ga}_{0.54} \mathrm{As}(\mathrm{Sb})$ followed by $50 \mathrm{~nm} \operatorname{In}_{0.62} \mathrm{Ga}_{0.38} \mathrm{P}$ tensile strained, repeated 2 times for a total thickness of $600 \mathrm{~nm}$. 